\title{
Improving Students' Proportional Thinking Using Schema-Based Instruction
}

\section{Citation}

Jitendra, Asha. K., Jon R. Star, Michael Rodriguez, Mary Lindell, and Fumio Someki. 2011. Improving Students' Proportional Thinking Using Schema-Based Instruction. Learning and Instruction 21, no. 6: 731-745.

\section{Published Version}

doi:10.1016/j.learninstruc.2011.04.002

\section{Permanent link}

http://nrs.harvard.edu/urn-3:HUL.InstRepos:9767981

\section{Terms of Use}

This article was downloaded from Harvard University's DASH repository, and is made available under the terms and conditions applicable to Open Access Policy Articles, as set forth at http:// nrs.harvard.edu/urn-3:HUL.InstRepos:dash.current.terms-of-use\#OAP

\section{Share Your Story}

The Harvard community has made this article openly available.

Please share how this access benefits you. Submit a story.

\section{Accessibility}




\begin{abstract}
This study investigated the effectiveness of an instructional program (schema-based instruction, SBI) designed to teach $7^{\text {th }}$ graders how to comprehend and solve proportion problems involving ratios/rates, scale drawings, and percents. The SBI program emphasized the underlying mathematical structure of problems via schematic diagrams, focused on a 4-step procedure to support and monitor problem solving, and addressed the flexible use of alternative solution strategies based on the problem situation. Blocking by teacher at three middle schools, the authors randomly assigned the 21 classrooms to one of two conditions: SBI and control. Classroom teachers provided the instruction. Results of multilevel modeling used to test for treatment effects after accounting for pretests and other characteristics (gender, ethnicity) revealed the direct effects of SBI on mathematical problem solving at posttest. However, the improved problem solving skills were not maintained a month later when SBI was no longer in effect nor did the skills transfer to solving problems in new domain-level content.
\end{abstract}

KEYWORDS: word problem solving, ratio and proportion, middle school students, schemabased instruction 


\section{Improving Students' Proportional Thinking Using Schema-Based Instruction}

\section{Introduction}

Problem solving is a central focus of current educational reforms in mathematics (Australian Education Council, 1990; Cockcroft, 1982; Department of Education and Employment [DfEE], 1999; National Council of Teachers of Mathematics, 2000; National Mathematics Advisory Panel, 2008; National Research Council, 2001). Foundational to problem solving in the middle grades is proportional thinking (reasoning with ratios, rates, and percentages), which requires "understanding the multiplicative relationships between rational quantities” (Boyer, Levine, \& Huttenlocher, 2008, p. 1478). Proportional thinking provides the bridge between the numerical, concrete mathematics of arithmetic and symbolic algebra and higher mathematics (e.g., Fuson \& Abrahamson, 2005; Lamon, 2007; Post, Behr, \& Lesh, 1988). However, children and adolescents experience difficulty with proportional thinking that extends into later years (Ahl, Moore, \& Dixon, 1992; Fujimura, 2001).

Proportional thinking, which is typically introduced in late elementary and middle schools in the form of word problems, is often used to teach "mathematical modeling and applied problem solving” (Van Dooren, De Bock, Hessels, Janssens, \& Verschaffel, 2005, p. 58). Word problems often involve short stories depicting relations between quantities (i.e., "The ratio of red to yellow roses in Monica's bouquet is 3 to 5 . The bouquet has a total of 2 dozen red and yellow roses. How many red roses are in Monica's bouquet?"). Proportion word problems such as this one are complex, in part because they require students to understand the language (i.e., grammatical rules of English) and factual information (e.g., 2 dozen $=12$ ) in the problem, identify relevant information (the ratio of the number of red roses to number of red and yellow 
roses) in the problem to create an adequate mental representation, and generate, execute, and monitor a solution strategy (Desoete, Roeyers, \& De Clercq, 2003; Mayer, 1999).

U.S. students' consistent difficulties in this domain call for effective instructional practices. Several recommendations are reported in the research literature for developing children's proportional thinking, including providing ratio and proportion tasks in a wide range of contexts (e.g., measurements, prices, rates) and ensuring that students have experienced conceptual instruction before presenting symbolic strategies such as the cross-product algorithm for solving proportional problems (Lamon, 1999; Van de Walle, 2007). Furthermore, designing instructional tasks that allow certain types of peer interactions may foster the development of mathematical thinking involved in proportional reasoning (Schwarz, \& Linchevski, 2007). In the present randomized controlled study, we rigorously evaluated the effectiveness of one instructional practice, schema-based instruction (SBI), which has shown promise in prior work (e.g., Jitendra et al., 2009).

\subsection{Research on Schema-Based Instruction and Problem Solving}

SBI is a promising instructional approach for improving mathematical word problem solving skills for both students at risk for poor problem solving outcomes as well as typically achieving students (e.g., L. S. Fuchs, D. Fuchs, Finelli, Courey, \& Hamlett, 2004; Jitendra et al., 2009). SBI is grounded in schema theory, which is based on the notion that acquisition of the problem schema, or underlying structure of the problem, is critical to successful problem solving (Kalyuga, 2006). For example, schema theory posits that organizing problems based on structural features (e.g., rate problem) as opposed to surface features (e.g., the problem's cover story) can induce the solution strategy necessary for effective problem solving. Schemata are cognitive knowledge structures held in long term memory that "allow us to treat multiple 
elements of information in terms of larger higher-level units (or chunks)” (Kalyuga, 2006, p. 2). Although initial schema acquisition entails working memory resources, use of schemata becomes automated with sufficient practice to require minimal working memory resources (Kalyuga, 2006).

The majority of research on the use of schemata in word problem solving has been conducted in the elementary grades, where analyses have identified several types of schemata (e.g., Change, Group, Compare) in the domain of arithmetic word problems (see Marshall, 1995). These schemata describe the semantic relations in story problems. For example, consider the following problem: Music Mania sold 56 CDs last week. It sold 29 fewer CDs last week than this week. How many CDs did it sell this week? (Jitendra, 2007, p. 118). Learners can be cued to the Compare schema for this problem through the relational sentence, “It [Music Mania] sold 29 fewer CDs last week than this week, "which illustrates the difference in the number of CDs sold last week to the number of CDs sold this week.

The use of schematic representations is a means to not only identify the underlying structure of problems but also model thinking by making apparent the mathematical relations among quantities in the problem situations (Steele, 2005). Schematic representations that can be used to interpret and elaborate on information in the problem lead to enhanced problem solving performance (Pape \& Tchoshanov, 2001). Such representations are essential components of many studies of SBI (e.g., Fuchs et al., 2009; Fuchs, Seethaler, et al., 2008; Fuson \& Willis, 1989; Griffin \& Jitendra, 2008; Jitendra et al., 2009; Jitendra, DiPipi, \& Perron-Jones, 2002; Jitendra, Griffin, Deatline-Buchman, \& Sczesniak, 2007; Jitendra et al., 2007; Jitendra, Griffin, McGoey, Gardill, Bhat, \& Riley, 1998; Jitendra \& Hoff, 1996; Jitendra, Hoff, \& Beck, 1999; Lewis, 1989; Willis \& Fuson, 1988; Xin, 2008; Xin, Jitendra, \& Deatline-Buchman, 2005; Xin \& 
Zhang, 2009; Xin, Wiles, \& Lin, 2008; Zawaiza \& Gerber, 1993). For example, Fuchs, Seethaler, et al. (2008) explored the effects of SBI for third graders identified as having mathematics and reading difficulties. The 35 students, who scored at the $10^{\text {th }}$ percentile in math and reading, were randomly assigned to the SBI or a control group that received regular mathematics classroom instruction. The SBI intervention in this study also focused on teaching students to transfer their word problem skills to more challenging problems that contained irrelevant information or novel questions that entailed an extra step, or relevant information presented in charts, graphs, or pictures. Results revealed that students in the SBI group improved their word problem solving performance compared to a control group. The effect size comparing the SBI group with the control group was large $(d=1.80)$.

Similarly, Jitendra and colleagues (Jitendra et al., 1998, Jitendra et al., 2007) worked with third graders who were randomly assigned to a SBI or control group. In both these studies, all students received comparable instructional time on problem solving heuristics, yet SBI was more effective than the control condition at enhancing students' mathematical word problem solving skills, regardless of whether classroom teachers delivered SBI in a whole-class format or researchers provided instruction in a small group arrangement. The effect sizes comparing the SBI group with the control group were moderate to large at immediate posttest ( $d=0.52$ to 0.65 ) and delayed posttest ( $d=0.69$ to 0.81 ). Further, SBI improved transfer to novel problems and the state standardized assessment $(d=0.65$ to 0.74$)$.

While the benefits of schema-based instruction are well-established with young children working on addition/subtraction word problem solving, less is known about the effectiveness of this approach in the middle grades with proportion word problems. In fact, given the substantial differences in the research on (and the content of) arithmetic vs. proportion word problems, there 
is some question as to whether SBI will be as effective in the middle grades. More specifically, there are three features of the arithmetic word problem landscape that have played key roles in the success of SBI - none of which applies to proportion word problems.

First, there is an extensive and mature literature in mathematics education that has identified a small set of agreed-upon arithmetic word problem types that completely characterize the domain. Carpenter and colleagues (Carpenter \& Moser, 1982; Carpenter, Hiebert, \& Moser, 1981) are generally credited with establishing the problem typology in this domain by identifying four problem types: Change, Combine, Compare, and Equalize. Across numerous studies in education and psychology (including existing research on SBI), researchers universally use this typology. Second and related, among SBI researchers, there are agreed-upon and very similar schemata for these four problem types. For the Compare problem type, for example, the schemata used by Fuchs and colleagues (e.g., Fuchs, Seethaler, et al., 2008), Jitendra and colleagues (e.g., Jitendra et al., 2009), and Fuson and colleagues (Fuson \& Willis, 1989) are almost identical. Finally, the range of mathematical topics that appear in arithmetic word problems is a small and clearly delineated set -- namely, addition and subtraction of integers. Although decimals and fractions would conceivably play a role in these problem types (e.g., the quantities in a Compare problem do not have to be integers), research on arithmetic word problem solving very rarely moves beyond addition and subtraction of integers. Overall, arithmetic word problem solving has proved to be an ideal domain in which to explore the effectiveness of SBI: in arithmetic word problems, there are a small number of agreed-upon types (that have agreed-upon schemata) that draw upon a tightly bounded set of mathematical topics. 
In contrast, the landscape of proportion word problem solving is considerably more murky - not because proportional reasoning has been less well-studied in mathematics education (quite the contrary; e.g., Fuson \& Abrahamson, 2005; Lesh, Post, \& Behr, 1988; Behr, Harel, Post, \& Lesh, 1992; Litwiller \& Bright, 2002; Lamon, 2007), but because it is less clear how to apply schema-based instructional techniques to word problem solving in this domain. There are few agreed-upon problem types for solving proportion problems, nor are there agreed-upon schemata. Researchers interested in using SBI for proportion word problems must first determine a set of problem types for this domain and then create schemata for these problem types.

A further complication is that proportional reasoning includes a broad set of mathematical topics whose boundaries are not easily identified. It seems clear that word problems involving ratio (e.g., "A drawer contains 6 green socks and 8 red socks. What is the ratio of green to red socks in the drawer?") and proportion ("The ratio of green to red socks is 3:4. There are 6 green socks. How many red socks are there?") should be included in the category of proportion word problems. But what about percents ("A drawer contains 6 green socks and 8 red socks. What percent of the socks in the drawer are red?"), percent change ("Two red socks are added to a drawer that already had 8 red socks. By what percent did the number of red socks in the drawer increase?"), interest ("Susan opens a bank account by depositing \$600; the bank offers a return of $6 \%$ per year simple interest. After two years, what will be the balance of Susan's bank account?"), and scale factor ("Gary built a model racecar that is 4 inches long and has a scale of 0.5 inch $=1$ feet. What is the length of the actual racecar?")? A strength of SBI is its focus on the identification of problem types, allowing learners to look beyond surface similarities of problems and consider underlying mathematical structure. Determining how to apply SBI in the domain of proportional word problems is clearly a non-trivial task. 
We were only able to locate two randomized controlled studies that have explored SBI with middle school students and ratio and proportion word problem solving, both by Jitendra and colleagues (Jitendra et al., 2009; Xin et al., 2005). These two studies serve as a foundation for the present study; they begin to map the landscape of proportion word problem solving and also provide initial evidence for the effectiveness of SBI in this domain.

First, in a study by Xin et al. (2005), 22 students with learning problems were randomly assigned to the SBI condition or a control condition that received instruction on the use of a general problem solving heuristic. Xin and colleagues chose to focus on a limited set of mathematical topics related to proportion: ratio problems and proportion problems. Results showed that students in the SBI condition significantly outperformed the control group on an immediate posttest $(d=1.69)$, delayed posttests $(d>2.50)$, and a transfer test $(d=0.89)$ that included items from standardized mathematics achievement tests.

More recently, Jitendra et al. (2009) addressed the potential benefits of SBI for 148 students from eight $7^{\text {th }}$ grade mathematics classrooms, with classrooms randomly assigned to SBI or "business as usual" control condition that received instruction on the same topics. This study extended prior work by Xin et al. (2005) in several ways, including a substantial expansion of the topics and schemata included within the intervention (including ratios, equivalent fractions, rates, and percents), the use of classroom teachers for providing instruction, an emphasis on multiple solution strategies, and the administration of a 4-month delayed posttest. The results of this study revealed that students in the SBI condition outperformed students in the control condition on the problem-solving immediate posttest $(d=0.45)$ and delayed posttest $(d=$ 0.56).

\subsection{Current Study}


In the present study, we build on the two studies described above to evaluate the effectiveness of SBI on seventh grade students’ learning to solve proportion problems involving ratios/rates and percents, in a randomized controlled trial. We addressed several limitations in research design of the Jitendra et al. 2009 study. We extended the class time allotted to the intervention significantly; we provided longer professional development to classroom teachers. In addition, we explored the robustness of SBI by conducting the study in two districts that used very different mathematics programs. Finally, we extended the focus of proportion problem solving to percents, including simple interest, to meet the district and state mathematics standards.

\subsection{Research questions and hypotheses}

The aim of the present study was to investigate the effectiveness of SBI, as compared to school-provided instruction, on students' problem solving performance. This article focuses on the direct effect of SBI on solving problems involving ratios/rates and percents, and only to a lesser degree on the indirect effect on transfer to novel problems. While the effect of SBI on the acquisition and retention of problem solving has been previously studied, the effect of SBI on students' transfer to novel problem is yet to be systematically evaluated.

Our first research question examined whether SBI leads to improved problem-solving performance compared to school-provided instruction. It was hypothesized that SBI would enhance students' problem solving skills more strongly than school provided instruction, because SBI uses a context-based approach to compare the structures of the different problems and help develop student understanding of the underlying mathematical concepts (e.g., ratios/rates, percents) (Hypothesis 1).

The second research question tested whether students' problem solving skills would be 
maintained even in the absence of SBI. It was predicted that SBI would influence the retention of problem solving skills more strongly than school-provided instruction, since SBI focuses on firm understanding of the underlying mathematical problem structures and concepts essential for accurate problem solution (Hypothesis 2).

The third research question examined whether the effect of SBI transfers to solving novel problems. The hypothesis was that the acquired problem solving skills would transfer to solving novel problems (e.g., probability, similar figures, measurement conversions) not directly within the learned domain content, but which also involve proportional reasoning (Hypothesis 3).

\section{Method}

\subsection{Design}

We used a pretest-intervention-posttest design with a retention test. Blocking by teacher at the 3 schools, we randomly assigned their classrooms to one of two conditions: Schema-based instruction (SBI; $n=283)$, and "business as usual" control $(n=153)^{1}$. Five of the six teachers had at least two SBI and at least one control class. Both of the sixth teacher's classrooms were assigned to the SBI condition.

\subsection{Participants}

Participants were drawn from 21 seventh-grade classrooms at three middle schools in two suburban school districts in Minnesota, which we refer to as Rosenblum and Celeroso. Both districts are moderately large (10,000 and 21,000 students, respectively), serve mostly white students (62\% and 57\%), with $34 \%$ and $16 \%$ reduced/free lunch. Students in the two schools from Rosenblum were using the MathThematics Book 2 textbook (Billstein, \& Williamson, 2008). Students in the middle school at Celeroso were using the Math Course 2 textbook 
(Larson, Boswell, Kanold, \& Stiff, 2007). Students using both textbooks had completed units on operations with fractions, integers, and decimals.

A total of six teachers volunteered to participate in the study: all four seventh-grade teachers at two middle schools in Rosenblum and two out of three seventh-grade teachers at one middle school in Celeroso. All teachers identified classes they felt were prepared to learn about ratios, proportions, and percents; students in the honors seventh-grade classrooms were not included in the study because they were learning advanced content from $8^{\text {th }}$ grade. A total of 482 (82\%) students obtained parental consent to participate in the study. Of these students, 7 were dropped from the analysis, 6 because they moved out of the schools and 1 because he was suspended and missed most of the intervention sessions. Furthermore, 39 students in the SBI condition that received supplemental small group tutoring were not included in the analysis. The remaining 436 students (218 female) had a mean age of 12.65 years (range $=11.9$ to 14.0 years; $S D=0.38$ ). The sample was 57\% Caucasian, 22\% African American, 13\% Hispanic, and 8\% American Indian and Asian American. Approximately 42\% of the sample received free or reduced lunch and 6\% were English language learners. The average score for participating students on the Mathematics Problem Solving subtest of the Stanford Achievement Test-10 (SAT-10 MPS; Harcourt Brace \& Company, 2003) administered in the fall was in the $61^{\text {st }}$ percentile (range $=1^{\text {st }}$ to $99^{\text {th }}$ percentile). Table 1 summarizes the demographic information and educational status information by condition. No statistically significant differences between the two groups were found for any of the variables.

The participating teachers (2 females and 4 males), whose mean age was 32.16 years, were all Caucasians and had a mean of 7.92 years of experience teaching mathematics (range 6 
to 10 years). Three of the teachers held secondary education certification, four had a master's degree, and two had an undergraduate degree in mathematics.

\subsection{Intervention}

Treatment and control group students received instruction from their classroom teachers on ratio, proportion, and percents and were introduced to the same topics (e.g., ratios, rates/proportions, scale drawings, fractions, decimals, and percents, percent of change) during the regularly scheduled mathematics instructional period for about 50 minutes daily, five days per week, across 29 school days. Students assigned to the control group received regular instruction outlined in their district-adopted mathematics textbooks, whereas the researcherdesigned SBI program replaced regular instruction on ratios, proportions, and percents for the treatment students.

\subsubsection{SBI}

The SBI program content is organized around two major units - Ratios/Proportions and Percents - that provide the basis for solving word problems involving ratios/rates and percents (see scope and sequence in Table 2). The SBI curriculum was developed by first conducting a content analysis of the topics of ratios, proportions, and percents covered in the two textbooks used in the participating $7^{\text {th }}$ grade classrooms and then mapping the key concepts and problemsolving skills to the two units. The first unit focused on building an understanding of ratios and rates that are critical to understanding proportions and for engaging in proportional reasoning as well as to solving ratio and proportion word problems. Unit 2 extended that understanding of ratios/rates to solve problems involving percents, which are a special type of ratios (i.e., a ratio that compares a number to 100). The scope and sequence of the SBI program addressed the content in the two textbooks and the Minnesota State Math Standards. 
The SBI program consisted of a series of 21 lessons (see Table 2). Lessons 1, 2, 5, and 11 focused on the underlying concepts (e.g., meaning of ratios, rates, percents) critical to solving ratio, proportion, and percent word problems. Lessons 3 and 4, 6 through 9, and 12 through 18 presented ratio, proportion, and percent problems in contexts, and the goal was to teach students to solve them using SBI. Lesson 19 consisted of classifying problems into the different problem types (ratio, proportion, percent) using a Jeopardy game format and transitioning from the use of schematic diagrams to represent the problem to representing the problem directly as a math equation. Lessons 10 and 20 presented a real-world context and had students solve several problems related to the real world example in order to evaluate knowledge of material presented in each of the two units. Lesson 21 culminated with a review of the SBI program content; in addition, student understanding and progress in the SBI program was evaluated using mid- and end-of-unit tests.

Across the 21 lessons, students are taught the following problem types: Ratio, proportion, scale drawing, percent involving part-whole comparison, percent of change (increase or decrease), and simple interest (see Table 3). Over time, students are led to the realization that ratios and percent problems describe multiplicative comparisons of two quantities and the same schematic (ratio) diagram can be used to depict the ratio context (the relationship between a part and a whole or between two distinct objects). Similarly, proportion and scale factor problems are alike in that they involve an If-Then statement of equality between two ratios/rates that allows one to think about the ways that two situations are the same. As such, the proportion schematic diagram depicts the situation involving two ratios/rates. While some percent of change problems are straightforward and involve only a ratio context (the relationship between the change amount and the original amount) or compare two ratio contexts, other percent of change problems and 
simple interest problems are more complex and involve both a ratio context that denotes a multiplicative comparison and a change context that is additive in nature. See Table 3 for the schematic diagrams for these problem types as part of the SBI program.

All instruction in the SBI program was scripted to ensure instructional consistency. However, teachers were encouraged to be familiar with the scripts to implement SBI effortlessly rather than read the scripts verbatim. Appendix A presents sample scripts from Lessons 5 and 6 involving rates and proportion problem solving to illustrate the nature and content of SBI. The key content goal of the SBI program was to teach students to identify the underlying structure of problems (ratio/proportion, percent), use schematic diagrams to represent the problem, and solve the problem using an appropriate solution strategy. The SBI program included DISC, a four-step problem solving procedure (D - Discover the problem type, I - Identify information in the problem to represent in a diagram, $\mathrm{S}$ - Solve the problem, $\mathrm{C}$ - Check the solution) and a checklist of the four steps to anchor student learning and promote metacognitive strategy knowledge. Each step was accompanied by questions designed to promote reflection of the problem solving behavior with regard to: (a) problem comprehension (e.g., Did I read and retell the problem to understand what is given and what must be solved? Why is this a proportion problem? How is this problem similar to or different from one I already solved?), (b) problem representation (e.g., What schematic diagram can help me adequately represent information in the problem to show the relation between quantities?), (c) planning (e.g., How can I set up the math equation? What solution strategy can I use to solve this problem?), and (d) problem solution (e.g., Does the answer make sense? How can I verify the solution?).

\subsubsection{Control Instruction}


Rosenblum students in classrooms using MathThematics Book 2 were presented with mathematical concepts and skills using real-world thematic modules. Each section in the rates, proportion, and percents module included one to three explorations, key concepts, practice and application exercises (including spiral review questions) and extra skill practice. For example, Section 3 emphasized solving proportions using cross products and interpreting graphs. The first of three explorations in this section focused on the effects of G-force on a roller coaster; the other two explorations extended this context, requiring students to graph and analyze data. Next, instruction targeted reviewing key concepts in the section followed by students completing practice and application exercises in class and as homework.

Celeroso students in classrooms using Math Course 2 were introduced to the topics of ratios and proportions by connecting these topics to previously learned concepts. The chapter presented real-life contexts for using ratios and proportions followed by review activities. Students and teachers discussed key concepts and completed example problems together. Practice exercises were assigned for in-class and homework completion.

\subsection{Measures}

\subsubsection{Student assessments}

Classroom teachers administered the student assessments using scripted directions in a whole-class arrangement.

\subsubsection{Assessing treatment effects}

To examine the extent to which students learned to solved problems involving ratios, proportions, and percents, an experimenter-designed mathematical problem-solving (PS) test that was modified from the one used in Jitendra et al. (2009) was administered (see Appendix B). The same assessment was used as a pretest, posttest, and delayed posttest (one month following 
instruction). The 20-item test included multiple-choice items derived from the TIMSS, NAEP and state assessments, with one short-answer conceptual item designed to tap students' knowledge of ratio concepts. Coefficient alpha for this measure was .68 for the pretest, .80 for the posttest, and .80 for the delayed posttest. With the exception of the conceptual item, all items were scored for accuracy of the answer. The mean interscorer agreement was $99.5 \%$ (range $=$ $97.9 \%$ to $100 \%$ ) for pretest, $99.7 \%$ (range $=97.9 \%$ to $100 \%$ ) for posttest, and $99.9 \%$ (range $=$ 99.3\% to $100 \%)$ for delayed posttest.

On the conceptual item, students explained their reasoning and this explanation was scored on a 4-point scale. A scoring template was constructed based on a sample $(n=9)$ of protocols that were randomly selected from both instructional conditions. Two research assistants first scored a sample of the protocols using the scoring criteria to obtain consensus followed by independent, blind scoring of the protocols (interscorer agreement on 30\% of explanations was 100\%).

To examine whether SBI impacted transfer, an experimenter-designed mathematical PS transfer test that was modified from the one used in Jitendra et al. (2009) was administered. The same assessment was used as a pretest and posttest. The 18-item test included novel and challenging content (e.g., probability) derived from the TIMSS, NAEP, and state assessments. Coefficient alpha was .70 for the pretest and .73 for the posttest. The mean interscorer agreement was $99.8 \%$ (range $=98 \%$ to $100 \%$ ) for pretest and $99.7 \%$ (range $=98 \%$ to $100 \%$ ) for posttest.

\subsubsection{Assessing treatment acceptability}

To evaluate student acceptability of the SBI program and its perceived effectiveness, students in the treatment condition only completed a modified version of the Treatment Acceptability Rating Form-Revised (TARF-R, Reimers \& Wacker, 1988) immediately following 
instruction (posttest). The rating scale consisted of nine items that students responded to by choosing the statements that best reflected their feelings: "strongly disagree," "somewhat disagree,” “somewhat agree,” and “strongly agree.” Example items included: “The diagrams helped me to organize information and understand how to solve problems," and "I found the DISC 4-step procedure and checklists helpful in checking my understanding of how to solve word problems.” Scoring of the items ranged from 1 (strongly disagree) to 4 (strongly agree) for a total possible score of 36. Coefficient alpha was .84.

\subsubsection{Teacher assessment}

\subsubsection{Teacher satisfaction questionnaire}

Teachers also completed a satisfaction questionnaire to determine their acceptability of the SBI program and its perceived effectiveness. The teacher version included 22 items focusing on the (a) overall intervention, (b) ratio, proportion, and percent diagrams, and (c) DISC problem solving procedure. Teachers rated each item on a 4-point scale, where 1 = "strongly disagree,” 2 = “somewhat disagree,” $3=$ "somewhat agree,” 4 = "strongly agree.” Example items included: “The teaching scripts were helpful in implementing the intervention," "I like the DISC checklists of problem solving steps used in this study," and "I will continue to use the diagrams in my classroom.” The questionnaire also included a section for teachers to write additional comments.

\subsubsection{Treatment fidelity}

We developed observation forms for measuring SBI and control classroom teachers' adherence to the assigned intervention or curriculum. For the control condition, the observation form examined teacher adherence to their curriculum in terms of percentage of information covered. We also recorded any deviations from their intended curriculum. For the treatment condition, the observation form focused on adherence to the scripted SBI protocols using a 
checklist of essential teacher instructional criteria (e.g., leads a discussion of critical concepts, models/guides students to solve the problem using the DISC 4-step strategy, monitors on-going student problem solving performance). Research assistants videotaped 57 observations of classroom instruction (19\% of the instructional sessions) in the treatment conditions and 21 observations (14\% of the instructional sessions) in the control condition during the 6-week intervention. We then randomly sampled 27 (47\%) videotaped classroom observations in the treatment conditions and 17 (81\%) videotaped observations in the control condition to check for fidelity of implementation. This sampling resulted in at least two observations per condition per teacher (range $=2$ to 6 ). Two observers viewed and independently rated each taped session using the observation criteria. Treatment fidelity to SBI protocols was measured using a dichotomous rating scale for each intervention step on the observation form. From these ratings, we also computed inter-observer agreements as number of agreements divided by number of agreements plus disagreements. The mean inter-observer agreement for the control condition was .99 (ranged from .96 to 1.00 ) for adhering to their curriculum. The mean inter-observer agreement for SBI protocol fidelity was .95 (.87 to 1.00$)$.

In addition to completing fidelity checklists, observers in both treatment and control classrooms also took detailed field notes about teacher and student interactions, instructional grouping, and classroom climate.

\subsection{Professional development}

All six teachers attended two one-day Professional Development (PD) sessions prior to the onset of intervention. The PD emphasized both the math content and effective implementation of the SBI intervention. Because teachers' classrooms were randomly assigned to intervention and control conditions, the two day PD sessions focused not only on the goals of 
the study and how to mediate instruction and facilitate discussions and group activities for both units (ratio and proportion; percent), but also emphasized the importance of implementing the standard "business-as-usual" curriculum faithfully in the control classrooms.

The professional development materials included: (a) presenting proportion and percent problems from the TIMSS assessment and engaging teachers in a discussion of how their students would approach these problem types as well as analyzing student solutions, explanations, and difficulties; (b) emphasizing the underlying structure of ratio, proportion, and percent problem types by identifying information in the problem to represent using schematic diagrams, (c) reviewing procedures inherent to the SBI approach via modeling and viewing a videotaped excerpt of a teacher implementing a SBI lesson as well as discussing how to elicit student discussions, and (d) having teachers read the lesson plans and discuss how to represent problems using schematic diagrams, explain common rules and procedures, monitor strategy knowledge, and analyze students’ solutions and explanations. In addition, project team members met with each teacher individually as needed to provide ongoing technical assistance throughout the duration of the study.

\section{Data Analysis Procedures}

First, we conducted preliminary analyses using independent samples $t$-test to examine the variables (e.g., gender, ethnicity, special education status, SES, ELL status) impacting the PS pretest scores. Then, we conducted multilevel (hierarchical) modeling to examine classroomlevel variance in pretest scores for the problem solving measure prior to the onset of intervention. The next set of analyses used multilevel modeling techniques to examine PS posttest, PS delayed posttest, and PS transfer posttest performance as a function of condition (SBI or control), controlling for pretest performance as well as other covariates based on the preliminary analysis. 
The same multilevel modeling approach was used with the PS posttest, delayed PS posttest, and PS transfer posttest data. Generally, at Level-1, student scores were modeled within classroom, adjusting for gender, ethnicity, and pretest scores.

$$
\text { Scores } \left._{i j}=\beta_{0 j}+\beta_{1 j}(\text { Male })_{i j}+\beta_{2 j}(\text { Ethnicity })_{i j}+\beta_{3 j} \text { (Pretest }\right)_{i j}+r_{i j}
$$

where $\beta_{0 j}$ is the estimate of the true classroom mean, controlling for Gender, Ethnicity, and Pretest differences among students; the individual student residual is normally distributed with a mean of zero and a constant variance, $r_{i j} \sim N\left(0, \sigma^{2}\right)$. Level-1 variables were group-mean centered to facilitate interpretation of the intercept $\beta_{0 j}$ as the classroom average performance for a given measure.

At Level-2, the classroom mean was then modeled as a function of classroom characteristics and condition (intervention v. control).

$$
\begin{gathered}
\beta_{0 j}=\gamma_{00}+\gamma_{01}(\text { Condition })_{j}+\gamma_{02}(\text { District })_{j}+\gamma_{03}(\text { PropMales })_{j}+\gamma_{04}(\text { PropEthnicity })_{j}+ \\
\gamma_{05}(\text { ACPretest })_{j}+u_{0 j}
\end{gathered}
$$

where $\gamma_{00}$ is the grand mean outcome in the population, adjusted for classroom differences between districts, the proportion of males and ethnic minority students, and average classroom pretest scores; where each school $j$ is associated with a random effect $u_{0 j} \sim \mathrm{N}\left(0, \tau_{00}\right)$. Level-2 variables were grand-mean centered.

The other effects at Level-1, including the Gender effect $\left(\beta_{1 j}\right)$, Ethnicity effect $\left(\beta_{2 j}\right)$, and Pretest effect $\left(\beta_{3 j}\right)$ were not modeled, as they were employed primarily for covariate value at Level-1. We used HLM (Raudenbush \& Bryk, 2002; Raudenbush, Bryk, \& Congdon, 2004) for all hierarchical analyses and conducted all other analyses using SPSS.

To estimate the practical significance of effects, we computed effect sizes by dividing the HLM coefficient for treatment effect, which represents the group mean difference adjusted 
for both level-1 and level-2 covariates, by the standard deviation of predicted classroom mean values (from $\tau_{00}$ ) prior to the inclusion of Condition in the model (Hedges, 2007). Further, we provide descriptive statistics for the treatment fidelity data as well as student and teacher acceptability of SBI.

\section{Results}

\subsection{Treatment fidelity and description of classroom instruction}

The mean treatment fidelity across teachers for the treatment classrooms averaged .86, with a range of .78 to 1.00 . The mean treatment fidelity for the control classrooms was .92 (ranged from .71 to .99) for adhering to their curriculum. The strong levels of implementation for the treatment classrooms are encouraging given that our intervention was novel to these teachers.

Recall that six teachers participated in the study; five teachers taught both treatment and control classrooms, whereas one teacher taught only treatment classrooms. Our observations of treatment classrooms indicated that five of the six teachers were able to consistently and comfortably implement the scripted lessons without reading them verbatim. These five teachers made minor adjustments to the pacing of lessons based on their perceptions of students' comprehension of the material, including occasional personalization of the content to increase student engagement (e.g., providing personal anecdotes to situate a word problem in local contexts). These five teachers also regularly made use of questioning to prompt student thinking in solving the problems.

One teacher was challenged by teaching from scripted lessons in his SBI classes, in that he had difficulty focusing instruction on critical information. Consequently, off-task and noncompliant classroom behaviors were more prevalent in this teacher's class and at times appeared to undermine implementation of instruction. In addition, our observations indicated that 
this teacher often did not demonstrate using a think-aloud procedure or require students to monitor and reflect on the problem solving behavior (e.g., Is this problem similar to or different from previously solved problems? Does the answer make sense?).

Of the SBI scripted lesson components, teachers showed the greatest variability in their implementation of the DISC 4-step checklist. Use of DISC was consistently strong in the initial lessons, but the DISC checklist was used less regularly in subsequent lessons, probably due to teachers' perception that most students did not need it. Observations indicated that Step 1 ("Discover the problem type") frequently was least likely to be discussed in detail by teachers. In particular, teachers either omitted or glossed over the details of discussing figuring out the type of problem and how it was like a previously solved problem.

With respect to control classrooms, although there was some individuality in the structure of the control classroom lessons, most teachers began each class by reviewing and solving homework problems on the board. The day's new material was then introduced, followed by opportunities for students to independently practice using the day's new skills (often with the teacher circulating around the room). Toward the end of the class, students were typically given time to work on their homework.

Teachers also varied in their instruction of problem solving strategies in their control classrooms. It is important to note that a key feature of SBI is its focus on multiple solution strategies, whereas students' regular texts relied exclusively on the cross multiplication strategy for solving ratio and proportion problems. However, two of the Rosenblum teachers frequently discussed multiple solution strategies when solving ratio and proportion problems.

\subsection{Preliminary analyses}


Results suggested that with the exception of ELL status, all other variables (gender, ethnicity, special education status, and free/reduced lunch) were significant in impacting PS pretest scores ( $t$-tests $p<.001)$ when tested simultaneously in a HLM model. Since ELL status overlapped considerably with ethnicity status, it was not included in the final model. After accounting for pretest scores, free/reduced lunch status was also not significant and not included in the final model. Further, results from our hierarchical pretest model revealed significant classroom variation $\left(\tau_{00}\right)$ on all measures $(p<.001)$; the intraclass correlation coefficient (ICC) for PS posttest, adjusted for PS Pretest (pre-existing differences), was .18, based on within classroom variance of $14.21\left(\mathrm{~s}^{2}\right)$ and between classroom variance of $2.59\left(\mathrm{t}_{00}\right)$, where the ICC $=$ 2.59/14.21.

\subsection{Direct treatment effects on posttests}

Observed group means and standard deviations are reported in Table 4. Results of the HLM analyses on the PS posttest, delayed posttest, and PS transfer posttest controlling for within and between classroom demographic differences and pretest scores on each measure are summarized in Table 5. The largest effect and only significant result is based on the PS posttest $(p=.01)$. The full result for the PS posttest model is provided in Table 6. After the final PS model, fully conditioned on Level 1 and 2 variables, the between classroom variance (variance of $u_{0}$ ) is no longer significant, as can be seen in the table of random effects. This suggests that the SBI condition led to more than a full-point gain (1.30) in PS posttest scores (a 20-item test) compared to the control classrooms. The effect size $(g)$ comparing the SBI group with the control group was 0.75 (based on classroom mean posttest $S D=1.74$, adjusted for pretest scores). The effect on PS delayed test $(g=0.49)$ was about two-thirds the size and not significant $(p=0.08)$. There was virtually no effect on the PS transfer posttest scores. 


\subsection{Treatment acceptability}

Results on treatment acceptability showed that student acceptability of the overall SBI $($ Mean $=26.39, S D=5.35)$ was moderately high $(73 \%)$. In general, students found the schematic diagrams $($ Mean $=13.27, S D=2.35)$ to be highly beneficial $(83 \%)$, and the average rating (Mean $=10.32, S D=3.23)$ for the DISC 4-step procedure was moderate $(65 \%)$.

Similarly, the six teachers' ratings of the effectiveness of the overall intervention (Mean $=6.8, S D=0.4$, total possible $=8)$ and schematic diagrams (Mean $=34.3, S D=4.1$, total possible $=40$ ) were strong and positive. In addition, teachers perceived the DISC 4-step procedure $($ Mean $=32.0, S D=4.2$, total possible $=40)$ as effective in helping students monitor their problem solving behavior.

\section{Discussion}

This purpose of this study was to evaluate the effectiveness of SBI for seventh grade students on solving proportion problems involving ratios/rates, scale drawings, and percents. Two earlier studies of the influence of SBI on proportional word problem solving performance have produced positive results (Jitendra et al., 2009; Xin et al., 2005). Neither study addressed percents as part of the broad category of proportional reasoning. In the current study, we extended the Jitendra et al. 2009 study by increasing the amount of instructional time; emphasizing percents, including simple interest, in the instructional unit on proportion word problems; providing longer professional development to teachers; and implementing the study in two school districts using very different mathematics programs. We hypothesized that students receiving SBI instruction would outperform their peers receiving "business-as-usual” instruction on measures of problem solving performance. Three major findings emerged: (a) significant differences were found between conditions on mathematical problem solving performance at 
posttest, favoring the SBI condition (Hypothesis 1); (b) no significant differences were found between conditions on the 1-month delayed posttest (Hypothesis 2); and (c) no significant differences were found between conditions on the transfer posttest (Hypothesis 3).

With respect to this first finding, results show that students in the SBI classes scored significantly higher than students in control classes on the mathematical problem-solving test at posttest (Hypothesis 1). Specifically, the effect size of 0.75 comparing the SBI treatment with the control group is consistent with earlier related work also conducted with seventh graders (Jitendra et al., 2009). It is also consistent with research on SBI on mathematics problem solving with elementary aged students (e.g., Fuchs, Seethaler, et al., 2008; Fuson \& Willis, 1989; Jitendra et al., 2007). Our finding also demonstrates that, even when compared with two very different mathematics programs, SBI with sufficient professional development and duration can positively impact students’ mathematical problem solving performance. Further, this finding extends prior work on teaching proportion problem solving using SBI to percents, a particularly challenging mathematical topic grounded in the previously learned concept of ratio (Lachance \& Confrey, 2002). In fact, results of an exploratory analysis of problem types indicated that the SBI condition was particularly instrumental in improving students' problem solving on percent problems ( $g=1.41, p=.02)$. Compared with the control group that did not receive instruction on the different problem types and thus likely perceived all problems as very different from previously solved problems, students in the SBI classrooms learned that the different problems could be categorized as ratio, proportion, or percent problems, which aided in their successful problem solving. Further, the SBI treatment focused on the similarities and differences among problems and related concepts to develop a firm understanding of the three constructs. As a result, students were able to recognize and accurately represent problems using the schematic 
diagrams and flexibly apply the solution methods appropriate to solve various problems. This finding, in particular, suggests that SBI can facilitate deep understanding and enhance students' proportional reasoning skills, especially when instruction makes explicit the connection between different content areas by focusing on the similarities and differences between the underlying problem structures of all three problems types (i.e., ratio, proportion, and percent).

Contrary to expectation and prior research on SBI (e.g., Jitendra et al., 2009; Xin et al., 2005), however, the results showed that SBI was not more effective in supporting students' retention of the problem solving skills than the control group (Hypothesis 2). Although one plausible explanation for the nonsignificant findings maybe due to low power, a more likely reason is the sequence of curriculum content that immediately followed the intervention. In the Jitendra et al. (2009) study, the delayed posttest followed instruction on percent problem solving using SBI, a topic that is closely related to the domain of proportional reasoning. In contrast, the content following ratios, proportions, and percents in the present study included geometric figures, measurement and area, surface area and volume, and probability. As such, the new domain content may have interfered with prior learning. At the same time, the effect size of 0.49 on the delayed posttest is encouraging when compared to the effect of 0.56 in the Jitendra et al. (2009) study. This finding suggests that future research examine greater curriculum continuity between our materials and subsequent content as well as determine optimal sample size to determine the effectiveness of SBI in helping students maintain their problem solving skills over time.

Similarly, there was also no evidence of an advantage of the SBI treatment to support transfer of the problem solving skills relative to the control group (Hypothesis 3). This finding parallels that of the Jitendra et al. (2009) study, which used a statewide mathematics achievement 
test to assess transfer. However, we expected that our transfer task, which included novel problems from a narrower content domain (proportionality and probability) than the broad mathematics achievement test in the Jitendra et al., would increase the likelihood of SBI student success in applying their schematic knowledge to solve the novel problems on this outcome task. In addition to the low power, the lack of contribution of SBI on transfer is due in part to differences between the posttest and transfer tests related to the problem types sampled even though items for both measures were derived from the TIMSS, NAEP, and state standardized mathematics assessments. Whereas the posttest restricted items to ratio, proportion, and percent problems encountered in seventh grade, the transfer test included items on probability, for example, that were less sensitive to the effects of SBI. A second possible explanation may be based on a contemporary perspective on transference of knowledge. Wagner's (2006) theory of transfer-in-pieces highlights the importance of multiple examples over earlier theories about the importance of abstracting principles underlying the specific classes of problems (e.g., Gentner, Loewenstein \& Thompson, 2003). Although our SBI provided sufficient examples and emphasized the critical features of the various problem types, it may be that longer duration of SBI is necessary to effect transfer. As Wagner pointed out, transfer is "the incremental growth, systematization, and organization of knowledge resources that only gradually extend the span of situations in which a concept is perceived as applicable” (p. 10). At the same time, given that students used SBI strategies to make the connection across ratio, proportion, and percent problem solving, transfer to other content (e.g., probability) could be effected by priming students to focus on the similarities and differences between the new domain and previously learned concepts of ratio. Future research should explore the performance of students when 
provided with even longer interventions and instruction that makes explicit connections to content outside of the instructional domain.

Although effects on the delayed posttest and transfer were not evident in this study, the contribution of SBI $(g=0.75)$ to problem solving following the intervention extends the work of Jitendra et al. (2009) in several ways. Whereas teachers in the Jitendra et al. implemented the study for 10 school days following 1 day of professional development, duration of the intervention for the current study was 6 weeks and included instruction of percents following two days of professional development. The duration of the professional development in our study provided teachers new to the SBI curriculum with the needed training to develop a "robust knowledge of mathematics and mathematical pedagogy...to teach precisely and rigorously” (Chard, Ketterlin-Geller, \& Jitendra, 2008, p. 233). Consequently, the fidelity of SBI implementation was higher (86\%) than in the Jitendra et al. (2009) study (80\%), which may have contributed, in part, to the potency of the SBI treatment despite the low power. Further, the present findings extend the work of Jitendra et al. by demonstrating the impact of SBI treatment for seventh graders across two quite different mathematics programs (i.e., Math Course 2, Larson, Boswell, Kanold, \& Stiff, 2007; MathThematics 2, Billstein \& Williamson, 2008) on the problem solving measure.

\subsection{Limitations}

Findings from this study should be considered in light of several limitations. First, although classroom teachers provided all instruction in this study, a substitute teacher took over instruction for 2 weeks at the beginning of the second unit (i.e., percent) for one of the teachers in the study. The substitute teacher received one day of professional development and taught both the SBI and control classrooms; the mean treatment fidelity of implementation for this 
novice teacher (who had recently completed his student teaching) was generally lower than the other teachers (45\% in the SBI classrooms compared to $67 \%$ in the control classrooms). It is possible that the substitute teacher's low level of SBI implementation may have undermined SBI student outcomes. Related to treatment fidelity implementation, our observations of classroom instruction indicated that two teachers at Rosenblum deviated somewhat from the strategy provided in their textbook (e.g., cross multiplication) by frequently discussing multiple solution strategies when solving ratio and proportion problems in their control classrooms. Further, one teacher challenged by teaching from scripted lessons in his SBI classes encountered persistent classroom management difficulties that possibly may have influenced student outcomes. Although the above situations may raise the issue of appropriate experimental control, it is important to point out that all of these variations in fidelity work against our hypotheses. The fact that SBI proved to be effective despite these variations is noteworthy. Nevertheless, future research is needed to examine in more detail whether benefits of SBI accrue when teachers are more familiar with the SBI materials.

Second, the present study does not allow us to isolate the effects of the different components (e.g., schematic diagrams, multiple solution methods, metacogntive strategy knowledge) of our SBI intervention. Therefore, future research should contrast the effects of SBI (that focuses on the underlying problem structure) with and without schematic diagrams, multiple solution methods, and metacogntive strategy knowledge. Third, our work on proportional reasoning was limited to problems involving linear relationships. However, overreliance on linear models may lead to the "illusion of linearity," when students apply the linear model to even nonproportional items (Van Dooren, De Bock, Hessels, Janssens, \& Verschaffel, 2004). As such, future research should consider non-proportional (e.g., additive) 
problems to better address expertise in proportional reasoning (e.g., discriminating between linear and nonlinear situations).

\subsection{Instructional Implications}

Despite these limitations, the present study shows that SBI is an effective approach for improving students' proportional problem solving performance. The benefits of SBI are further supported by the positive evaluation of the intervention by students and teachers, especially with regard to the schematic diagrams. Based on the findings from this study, we provide two implications for instructional practice, First, teachers need to provide instruction on using schematic diagrams that are appropriate for the problems, support the use of multiple ways to solve problems, and model how to monitor and reflect on the problem solving process. These are essential features to include in problem solving instruction to promote understanding of mathematical ideas that are requisite for mathematical reasoning and flexibility required in more advanced mathematics (e.g., algebra, geometry, trigonometry, and calculus). Decision-making about teaching one or all of these essential features might require using more than the one item assessing students' conceptual understanding that we used on the posttest to make student thinking visible. Second, teachers need to optimize learning opportunities to help students transfer from ratio, proportion, and percent problems to other content, such as probability. This would mean helping students understand how they might apply their understanding of the concept of ratio to solve more challenging problem types (e.g., probability, similar figures, linear equations). 


\section{References}

Ahl, V. A., Moore, C. F., \& Dixon, J. A. (1992). Development of intuitive and numerical proportional reasoning. Cognitive Development, 7, 81-108. doi:10.1016/08852014(92)90006-D

Australian Education Council (1990). A national statement on mathematics for Australian schools. Carlton, Australia: Curriculum Cooperation.

Behr, M., Harel, G., Post, T., \& Lesh, R. (1992). Rational number, ratio and proportion. In D. Grouws (Ed.), Handbook of Research on Mathematics Teaching and Learning (pp. 296333). NY: Macmillan Publishing.

Billstein, R., \& Williamson, J. (2008). Math thematics: Book 2 (new edition). Evanston, IL: McDougal Littell.

Boyer, T. W., Levine, S. C., \& Huttenlocher, J. (2008). Development of proportional reasoning: Where young children go wrong. Developmental Psychology, 44, 1478-1490. doi: $10.1037 / \mathrm{a} 0013110$

Carpenter, T. P., Hiebert, J., \& Moser, J. M. (1981). Problem structure and first-grade children’s initial solution processes for simple addition and subtraction problems. Journal for Research in Mathematics Education, 12(1), 27-39. Retrieved from http://www.jstor.org/stable/748656

Carpenter, T. P., \& Moser, J. M. (1982). The development of addition and subtraction problem solving skills. In T. P. Carpenter, J.M. Moser. \& T. A. Romberg (Eds.), Addition and subtraction: A cognitive perspective (pp. 9-24). Hillsdale, NJ: Erlbaum.

Chard, D. J., Ketterlin-Geller, L. R., \& Jitendra, A. (2008). Systematic instruction and assessment to improve mathematics achievement for students with disabilities: The 
potential and promise of RTI. In E. L. Grigorenko (Ed.), Education individuals with disabilities: IDEIA 2004 and beyond (pp. 227-246). New York: Springer.

Cockcroft, W. H. (1982). Mathematics counts (Report of the Committee of Inquiry Into the Teaching of Mathematics in Schools). London: Her Majesty's Stationery Office.

Desoete, A., Roeyers, H., \& De Clercq, A. (2003). Can offline metacognition enhance mathematical problem solving? Journal of Educational Psychology, 95, 188-200. doi: 10.1037/0022-0663.95.1.188

Department for Education and Employment (DfEE) (1999). The National Numeracy Strategy: A framework for teaching (London, DfEE).

Fuchs, L. S., Fuchs, D., Finelli, R., \& Courey, S. J., \& Hamlett, C. L., (2004). Expanding schema-based transfer instruction to help third graders solve real-life mathematical problems. American Educational Research Journal, 41(2), 419-445. doi: $10.3102 / 00028312041002419$

Fuchs, L. S., Powell, S. R., Seethaler, P. M., Cirino, P. T., Fletcher, J. M., Fuchs, D., Hamlett, C. L., \& Zumeta, R. O. (2009). Remediating number combination and word problem deficits among students with mathematics difficulties: A randomized control trial. Journal of Educational Psychology, 101, 561-576. doi:10.1037/a0014701

Fuchs, L. S., Seethaler, P. M., Powell, S. R., Fuchs, D., Hamlett, C. L., \& Fletcher, J. M. (2008). Effects of preventative tutoring on the mathematical problem solving of third-grade students with math and reading difficulties. Exceptional Children, 74(2), 155-173. Retrieved from http://vnweb.hwwilsonweb.com/hww/results/external_link_maincontentframe.jhtml?_DAR GS=/hww/results/results_common.jhtml.44

Fujimura, N. (2001). Facilitating children's proportional reasoning: A model of reasoning 
processes and effects of intervention on strategy change. Journal of Educational Psychology, 93(3), 589-603. doi: 10.1037/0022-0663.93.3.589

Fuson, K.C., \& Abrahamson, D. (2005). Understanding ratio and proportion as an example of the apprehending zone and conceptual-phase problem-solving models. In J. Campbell (Ed.), Handbook of mathematical cognition (pp. 213-234). New York: Psychology Press.

Fuson, K. C., \& Willis, G. B. (1989). Second graders’ use of schematic drawings in solving addition and subtraction word problems. Journal of Educational Psychology, 81, 514-520. doi:10.1037/0022-0663.81.4.514

Gentner, D., Loewenstein, J., \& Thompson, L. (2003). Learning and transfer: A general role for analogical encoding. Journal of Educational Psychology, 95(2), 393-408. doi: $\underline{10.1037 / 0022-0663.95 .2 .393}$

Griffin, C. C. \& Jitendra, A. K. (2008). Word problem solving instruction in inclusive third grade mathematics classrooms. Journal of Educational Research, 102(3), 187-202. doi: 10.3200/JOER.102.3.187-202

Hedges, L. V. (2007). Effect sizes in cluster-randomized designs. Journal of Educational and Behavioral Statistics, 32, 341-370. doi:10.3102/1076998606298043

Jitendra, A., DiPipi, C. M., \& Perron-Jones, N. (2002). An exploratory study of schema-based word problem solving instruction for middle school students with learning disabilities: An emphasis on conceptual and procedural understanding. The Journal of Special Education, 36, 23-38. doi:10.1177/00224669020360010301

Jitendra, A. K., Griffin, C., Deatline-Buchman, A., \& Sczesniak, E. (2007). Mathematical word problem solving in third grade classrooms. Journal of Educational Research, 100(5), 283-302. doi:10.3200/JOER.100.5.283-302 
Jitendra, A. K., Griffin, C., Haria, P., Leh, J., Adams, A., \& Kaduvetoor, A. (2007). A comparison of single and multiple strategy instruction on third grade students' mathematical problem solving. Journal of Educational Psychology, 99(1), 115-127. doi: 10.1037/0022-0663.99.1.115

Jitendra, A. K., Griffin, C., McGoey, K., Gardill, C, Bhat, P., \& Riley, T. (1998). Effects of mathematical word problem solving by students at risk or with mild disabilities. Journal of Educational Research, 91(6), 345-356. doi:10.1080/00220679809597564

Jitendra, A., \& Hoff, K. (1996). The effects of schema-based instruction on mathematical word problem solving performance of students with learning disabilities. Journal of Learning Disabilities, 29(4), 422-431. doi:10.1177/002221949602900410

Jitendra, A. K., Hoff, K., \& Beck, M. M. (1999). Teaching middle school students with learning disabilities to solve word problems using a schema-based approach. Remedial and Special Education, 20(1), 50-64. doi:10.1177/074193259902000108

Jitendra, A. K., Star, J., Starosta, K., Leh, J., Sood, S., Caskie, G., Hughes, C., \& Mack, T. (2009). Improving students’ learning of ratio and proportion problem solving: The role of schema-based instruction. Contemporary Educational Psychology, 34, 250-264. doi:10.1016/j.cedpsych.2009.06.001

Kalyuga, S. (2006). Rapid cognitive assessment of learners’ knowledge structures. Learning and Instruction, 16, 1-11. doi:10.1016/j.learninstruc.2005.12.002

Lachance, A., \& Confrey, J. (2002). Helping students build a path of understanding from ratio and proportion to decimal notation. Journal of Mathematical Behavior, 20, 503-526. doi:10.1016/S0732-3123(02)00087-1

Lamon, S. J. (1999). Teaching fractions and ratios for understanding: Essential content 
knowledge and instructional strategies for teachers. Mahwah, NJ: Erlbaum.

Lamon, S. J. (2007). Rational numbers and proportional reasoning: Toward a theoretical framework for research. In F. K. Lester, Jr. (Ed.), Second handbook of research on mathematics teaching and learning (pp. 629-668). National Council of Teachers of Mathematics, Charlotte, NC: Information Age Publishing.

Larson, R., Boswell, L., Kanold, T. D., \& Stiff, L. (2007). Math course 2. Evanston, IL: McDougal Littell.

Lesh, R., Post, T., \& Behr, M. (1988). Proportional Reasoning. In J. Hiebert \& M. Behr (Eds.) Number Concepts and Operations in the Middle Grades (pp. 93-118). Reston, VA: Lawrence Erlbaum \& National Council of Teachers of Mathematics.

Lewis, A. B. (1989). Training students to represent arithmetic word problems. Journal of Educational Psychology, 8, 521-531. doi:10.1037/0022-0663.81.4.521

Litwiller, B., \& Bright, G. (2002). Making sense of fractions, ratios, and proportions. Reston, VA: National Council of Teachers of Mathematics.

Marshall, S. P. (1995). Schemas in problem solving. New York: Cambridge University Press.

Mayer, R. E. (1999). The promise of educational psychology Vol. I: Learning in the content areas. Upper Saddle River, NJ: Merrill Prentice Hall.

National Council of Teachers of Mathematics (2000). Principles and Standards for School Mathematics. Reston, VA: Author.

National Mathematics Advisory Panel (2008). Foundations for Success: The Final Report of the National Mathematics Advisory Panel. Washington, DC.: U.S. Department of Education. 
National Research Council (2001). Adding it up: Helping children learn mathematics. J. Kilpatrick, J. Swafford, and B. Findell (Eds.) Mathematics Learning Study Committee, Center for Education, Division of Behavioral and Social Sciences and Education. Washington, DC: National Academy Press.

Pape, S. J., \& Tchoshanov, M. A. (2001). The role of representation(s) in developing mathematical understanding. Theory into Practice, 40, 118-127. Retrieved from http://www.jstor.org/stable/1477273

Post, T. R., Behr, M. J., \& Lesh, R. (1988). Proportionality and the development of prealgebra understandings. In A. Coxford \& A. Shulte (Eds.), The ideas of algebra, K-12 (pp. 78-90). Reston, VA: National Council of Teachers of Mathematics.

Raudenbush, S. W., \& Bryk, A. S. (2002). Hierarchical linear models: Applications and data analysis methods (2nd ed.). Thousand Oaks, CA: Sage Publications.

Raudenbush, S.W., Bryk, A.S, \& Congdon, R. (2004). HLM 6 for Windows (Version 6.04) [Computer software]. Lincolnwood, IL: Scientific Software International.

Reimers, T. M., \& Wacker, D. P. (1988). Parents' ratings of the acceptability of behavioral treatment recommendations made in an outpatient clinic: A preliminary analysis of the influence of treatment effectiveness. Behavioral Disorders, 14(1), 7-15.

Steele, D. (2005). Using writing to access students' schemata knowledge for algebraic thinking. School Science and Mathematics, 105, 142-154. doi:10.1111/j.1949-8594.2005.tb18048.x

Schwarz, B. B., \& Linchevski, L. (2007). The role of task design and argumentation in cognitive development during peer interaction: The case of proportional reasoning. Learning and Instruction, 17, 510-531. doi:10.1016/j.learninstruc.2007.09.009 
Van de Walle, J.A. (2007). Elementary and middle school mathematics: Teaching developmentally (6 $6^{\text {th }}$ ed.). Boston: Pearson Education.

Van Dooren, W., De Bock, D., Hessels, A., Janssens, D., \& Verschaffel, L. (2004). Remedying secondary school students' illusion of linearity: a teaching experiment aiming at conceptual change. Learning and Instruction, 14, 485-501. doi:10.1016/j.learninstruc.2004.06.019

Van Dooren, W., De Bock, D., Hessels, A., Janssens, D., \& Verschaffel, L. (2005). Not everything is proportional: Effects of age and problem type on propensities for overgeneralization. Cognition \& Instruction, 23, 57-86, 30 . doi: 10.1207/s1532690xci2301_3

Wagner, J. (2006). Transfer in pieces. Cognition and Instruction, 24(1), 1-71. doi: 10.1207/s1532690xci2401_

Willis, G.B., \& Fuson, K.C. (1988). Teaching children to use schematic drawings to solve addition and subtraction word problems. Journal of Educational Psychology, 80(2), 191201. doi: 10.1037/0022-0663.80.2.192

Xin, Y. P. (2008). The effects of schema-based instruction in solving mathematics word problems: An emphasis on prealgebraic conceptualization of multiplicative relations. Journal for Research in Mathematics Education, 39(5), 526-551. Retrieved from http://www.nctm.org/eresources/article_summary.asp?URI=JRME2008-11-526a\&from=B

Xin, Y. P., Jitendra, A. K., \& Deatline-Buchman, A. (2005). Effects of mathematical word problem solving instruction on students with learning problems. Journal of Special Education, 39(3), 181-192. doi: 10.1177/00224669050390030501 
Xin, Y. P., Wiles, B., \& Lin, Y-Y. (2008). Teaching conceptual model based word problem story grammar to enhance mathematics problem solving. Journal of Special Education, 42, 163178. doi:10.1177/0022466907312895

Xin, Y. P., \& Zhang, D. (2009). Exploring a conceptual-model based approach to teaching situated word problems. Journal of Educational Research, 102(6), 427-441. doi: 10.3200/JOER.102.6.427-442

Zawaiza, T. B. W., \& Gerber, M. M. (1993). Effects of explicit instruction on math wordproblem solving by community college students with learning disabilities. Learning Disabilities Quarterly, 16(1), 64-79. Retrieved from http://www.jstor.org/stable/1511159 


\section{Footnote}

${ }^{1}$ The present study originally included a third condition. In this slight variation of the SBI condition (SBI + Tutoring), some struggling students received additional pull-out small-group tutoring. However, inclusion of SBI + Tutoring as a distinct condition analytically separate from SBI proved quite problematic, primarily because of the wide variation in implementation across the two districts. Although small-group tutoring was provided by trained research staff, the two districts were given considerable latitude in determining which students should/could attend the tutoring sessions, when tutoring sessions would occur, whether attendance was compulsory, and the frequency, class size, and duration of the sessions. For example, in one district, tutoring class sizes were large ( $n=5$ to 8 students), tutoring sessions lasted 30 minutes, attendance was compulsory, and total tutoring time for the entire study was 450 minutes. In contrast, in the other district, tutoring classes were smaller ( $n=2$ to 5) because attendance was not compulsory, and total tutoring time was substantially longer (900 minutes). Given the wide disparity in implementation, it seemed problematic to combine the two districts into a single SBI + Tutoring condition. It is also worth noting that the vast majority of students in the SBI + Tutoring condition did not attend any tutoring sessions and thus were actually experiencing the SBI condition; of the 166 students originally assigned to this condition, only 26 (16\%) of the 39 students assigned to receive tutoring consistently attended the tutoring sessions. As such, the 39 students who received tutoring were excluded from the analysis, and both SBI + Tutoring and SBI conditions were combined and are referred to in all subsequent analyses as the SBI or treatment condition. At the same time, outcomes did not reliably differ when these the 39 students who received small group tutoring were excluded fromincluded in the analysis. 